\title{
Legal and Ethical Aspects of Pain Management
}

\author{
Marko Jukić ${ }^{1}$, Livia Puljak ${ }^{2,3}$ \\ ${ }^{1}$ Department of Anesthesiology and \\ Intensive Care Medicine, University \\ Hospital Split, Split, Croatia, ${ }^{2}$ Laboratory \\ for Pain Research, University of Split \\ School of Medicine, Split, Croatia, ${ }^{3}$ Agency \\ for Quality and Accreditation in Health \\ Care and Social Welfare, Zagreb, Croatia
}

Received: 30 December 2017

Accepted: 11 April 2018
In this manuscript we presented legal and ethical aspects of pain management. Pain is a global public health problem because the burden of acute and chronic pain is considerable and is continuously increasing. It has been postulated that pain management is a fundamental human right, and that health systems are obliged to ensure universal access to pain management services. The suggestion that pain management is a right was fuelled by ample evidence about inadequate treatment of pain. Undertreatment and underprescribing in the context of pain can potentially have serious legal consequences, including charges about negligence, elder abuse, manslaughter and euthanasia. Multiple international declarations by professional societies have outlined pain management as a core ethical duty in medicine. Therefore, healthcare professionals need to be aware of multiple facets of pain-related ethics, including appraisal of patient's decision-making capacity. The worldwide opioid crisis also calls for careful consideration of specific ethical issues. Finally, healthcare workers need to be aware of the the risks associated with promoting pain management as a human right because patients and their caretakers can mistakenly perceive that they have right to total analgesia. Conclusion. Patients do have the right to pain management, but patient rights have limits, which may interfere with other competing rights, and also rights of their physicians. Treatment of pain must be medically, ethically and economically justified. Healthcare workers have an obligation to continuously improve their Key words: Pain - Ethics - Law - Patient- knowledge about pain management, including medical, legal and ethiphysician relationship. cal aspects of pain.

\section{Introduction}

The treatment of pain is a public health priority because the global burden of acute and chronic pain is considerable and it is continuously increasing (1). A recent analysis of the burden of chronic pain without clear etiology in individuals living in low and middleincome countries (LMIC) indicated that the prevalence of unspecified chronic pain is $34 \%$ in the general population living in LMICs, with $42 \%$ of the general population suffering from a headache, and $21 \%$ from low back pain (2). This analysis included 119 research reports from 28 LMICs, and the authors highlighted a high heterogeneity in results and assessment of global chronic pain (2).

The burden of chronic pain is pervasive not only in LMICs, but across the globe. This is supported by results of the Global Burden of Disease Study 2013, published in 2015, which analyzed global, regional and national incidence, prevalence and years lived with disability for as many as 301 diseases, both acute and chronic, and injuries in 188 countries between 1990 and 2013 (3). Their results indicated that 
among the top ten diseases/conditions that caused disability, low back pain was ranked at the first place, while chronic neck pain and migraine were ranked 4th and 6th, respectively. Two mental health conditions were also among the top 10, including major depressive disorder and anxiety (3); this is important in the context of pain because it is known that depression and anxiety are important comorbidities with chronic pain (4).

Chronic pain commands attention because it is usually difficult to treat, particularly certain types such as neuropathic pain (5). Currently, there is an ongoing debate whether chronic pain is a disease in its own right (6-9). However, acute pain is also a significant burden, despite myriad available treatment options for the management of such pain. Numerous recent studies have shown that acute pain is very prevalent across the globe, even when it is preventable. For example, a systematic review of acute pain in hospitalized patients, published in 2016, indicated that the prevalence of such pain ranged from 38 to $84 \%$, while prevalence of severe pain ranged from 9 to $36 \%$ (10). The manuscript analyzed 14 studies published from 1990 to 2013, included data from 9 countries, which involved a total of 23,523 patients from 56 hospitals (10).

Newer studies show similar data trends, indicating the high prevalence of pain in the hospital setting, lack of attention to available guidelines, and insufficient prescribing of pain medications (11-13). This is even found in the case of postoperative pain after major surgical procedures (14).

Furthermore, the socioeconomic impact of acute and chronic pain is severe. Pain is one of the leading reasons for absence from work in the USA, where lost productive time from common pain conditions among active workers translates into major costs (15). Gaskin and Richard have shown that the total incremental cost of healthcare that can be attributed to pain ranged from 261 to
300 billion USD. They valued lost productivity with three different estimates, including missed days of work (estimated at up to 12.7 billion USD), lost hours of work (up to 96.5 billion USD and lower wages (up to 225 billion USD). The total calculated cost of pain to society, including healthcare costs and all three productivity estimates, ranged from 560 to 635 billion USD in 2010 dollars (16). Based on the authors' results, the annual cost of pain in the USA was higher than the annual cost of heart disease (estimated at 309 billion USD), cancer (243 billion USD) or diabetes (188 billion USD) (16).

It needs to be emphasized that while attention to pain has increased in the international research community, the attention is shifting to different topics. For example, analysis of manuscripts published in a prominent pain-related journal from 1975 to 2007 indicated that the percentage of studies analyzing interventions in humans declined precipitously with time as a percentage of publications, replaced with an increased number of animal studies about behavioral pharmacology (17). Furthermore, it was recently emphasized that attention to pain is swinging between extremes and represents a moving target, with most of the articles in lay press highlighting the problems associated with opioid analgesics, while neglecting significant benefits that can be accrued from their appropriate use (18). There are still areas of the world where the use of opioids is insufficient considering the estimated burden of disease (19).

The aim of this manuscript was to present legal and ethical aspects of pain management, with regards to relevant references and new developments in the field of pain.

\section{Pain management is a fundamental human right}

It has been postulated that pain management is a fundamental human right, and 
that health systems are obliged to ensure universal access to pain management services on a nondiscriminatory basis including provision of basic medications for treatment of pain and implementation of national pain policies $(20,21)$.

After recognizing that pain management is a human right, the next challenge is to ensure implementation of appropriate medical and social changes that will make pain management a core component of healthcare (22). Pain management is a core ethical duty in medicine (20). Frustrated by the slow pace of medical, cultural, legal, and political change, many within the community of pain clinicians have begun to promote the status of pain management beyond that of appropriate clinical practice or even an ethic of good medicine (20).

\section{Law and management of pain: Negligence, elderly abuse, euthanasia}

In common law, the suggestion of negligence provides a further possible legal foundation that should ensure adequate pain management. Margaret Somerville, Professor of Law and Medicine at McGill University, has long argued that the unreasonable failure to provide adequate pain management constitutes negligence (23). The law of medical negligence emphasizes taking reasonable care in all aspects of patient management. When approaching a physician, patients expect medical treatment that will relieve their medical problems. A physician owes certain duties to patients and breach of these duties may give a cause of action for negligence against a physician (24). Undermedication of pain has also been called a moral negligence (25).

With respect to pain control, doctors may breach their standard of care by failing to take an adequate pain history from the patient; by treating the pain inadequately; and, in the context of uncontrolled pain, by failing to consult an expert in pain management (26). Several such cases of legal actions involving pain-related negligence have already appeared; they have even been described in medical literature, reporting that millions in damages were paid because of gross negligence associated with undertreatment of pain and suffering (27). Ben A. Rich has warned physicians: "Another message to physicians implicit in these verdicts is that there is a standard of care for pain management, a significant departure from which constitutes not merely malpractice but gross negligence. Even if professional boards might not hold their licensees to that standard, juries will" (27).

One of those cases indicates that geriatric setting is yet another area of jurisprudence that may be associated with legal aspects of pain management $(27,28)$. In a case of Bergman vs Chin it was argued that according to California's Elder Abuse and Dependent Adult Civil Protection Act, inadequate pain management of an elderly person may be considered a case of elderly abuse (28).

Pain management of terminal patients is yet another potential legal problem because some pain medications can be life threatening. Severe adverse events, including deaths, are the most commonly reported adverse effects of opioids (29). It has been argued that giving pain medication to terminal patients could be mistaken for a manslaughter and a sort of euthanasia (30). This legal problem for physicians could be prevented by consulting physicians specialized in pain management such as those employed in pain clinics (31). Furthermore, physicians need to take due care to avoid such risk of being liable, including taking an informed consent for treatment, observing a proportionality rule, and accurate keeping of medical records (30). With time, more cases may emerge to better outline the boundaries of reasonable action by doctors, nurses, and pharmacists in pain management (26). 


\section{Ethics and management of pain}

The management of pain has been postulated as a "core ethical duty in medicine" (22). The responsibilities of doctors to their patients are primarily ethical. Right to a pain management could be considered as an example of a bioethical principle of beneficence, or doing good for others, which is an ethical principle that is particularly prominent in medicine (32). This principle was ingrained in a number of key documents and declarations adopted by relevant international medical organizations.

According to the Americal Medical Association (AMA)'s Code of Ethics, 'physicians have an obligation to relieve pain and suffering" (33). Since 1947, the World Medical Association (WMA) has been developing a system of ethical obligations or a professional deontology, which elaborates the physician's role versus the rights of individual patients. In 1948, the WMA published a Declaration of Geneva, which was proclaimed to be "the contemporary successor to the 2500-year-old Hippocratic Oath" (34). One of the principles of the Declaration of Geneva is "the health and well-being of my patient will be my first consideration" (34). Professional associations of healthcare personnel in many countries have adopted a similar ethical basis for the management of pain (20). The WMA has also brought forward the International Code of Medical Ethics in 1949, last updated in 2006 (35). Both in this Code and in Declaration of Geneva, patient rights are presented as the result of the matrix of obligations of a physician towards a patient $(34,35)$.

In 1964, the WMA adopted a Declaration of Helsinki $(\mathrm{DoH})$ as the first international document prescribing rules for medical research involving human subjects (36). The purpose of $\mathrm{DoH}$ was to provide guidance to those involved in clinical research, and therefore its main focus was a responsibility of a researcher regarding protection of humans as research subjects. The DoH defined requirement to obtain informed consent of participants, as a measure for protecting an individual's autonomy. Initially this was meant as a protection against unwanted inclusion in experimentations, but informed consent later became generally accepted standard for consenting to a medical treatment, as specified in the WMA's Declaration of Lisbon on the rights of the patient, which was first adopted in 1981 (37).

Together with the bioethical principle of beneficence, the principle of nonmaleficence is also crucial in medicine, which prohibits the infliction of harm (38). Failure to reasonably treat patients' pain and suffering causes harm could, therefore, be considered an ethical breach of maleficence (39).

The American Academy of Pain Medicine (AAPM) has therefore adopted the ethics charter, which requires all physicians to improve in a number of pain-related areas, including assessment of pain, treatment of pain with competence and compassion, education in principles of pain medicine, support to pain-related research and engagement in advocacy that will ensure access to pain management and its continuous improvement (40).

International Association for the Study of Pain (IASP) also took a stand on the issue of ethics and pain, by adopting a Declaration of Montreal during the First International Pain Summit on September 3, 2010, which states that access to pain management is a fundamental human right (41). IASP was founded in 1973 and it is the largest multidisciplinary international organization in the field of pain, which "brings together scientists, clinicians, health-care providers, and policymakers to stimulate and support the study of pain and translate that knowledge into improved pain relief worldwide" (42). As the foremost global organization devoted to pain research and management, 
IASP has endorsed numerous ethical principles and declarations about including humans in research endeavours (43).

\section{Decision-making capacity in patients with pain: Ethical and legal issue}

Physicians who treat patients suffering from pain need to be aware about their patients' decision-making capacity. Pain can also be a factor that negatively affects decision-making capacity. Iatrogenic causes can contribute to diminished patient's decision-making capacity. Therefore, physicians treating pain have an ethical and legal obligation to assess and evaluate patient's decision-making capacities (40). Assessing whether a patient has capacity to make informed decisions about his or her medical care is something that physicians are frequently required to do (44). According to the AAPM, giving autonomous informed consent requires from a patient: i) understanding of information and consequences, ii) demonstration of insight, iii) reason and judgment, iv) the ability to evince a decision or articulate a preference and $\mathrm{v}$ ) voluntariness (40).

Physician needs to respect patient's wishes and values. All five criteria must be met for informed decision-making. If a patient cannot meet these criteria, a surrogate decisionmaker needs to be involved. Alternatively, autonomy of patients with diminished or impaired decision-making capacity can be promoted by giving them degree of autonomy commensurate with their capabilities (45).

Sometimes, a physician may perceive that a surrogate decision-maker is not suggesting actions that are in the patient's best interest. Ethical and legal obligation of a physician is to advance welfare of a patient. If necessary, an attending physician may consult institutional ethics committee to seek help regarding medical decisions. Ethics committee needs to be the first instance to refer such a dispute before resorting to legal actions (45).

\section{Ethics of opioid prescribing for pain management}

Use of opioids for pain management has recently emerged as a particular ethical problem, particularly in the setting of treating non-malignant chronic pain $(46,47)$. Overprescription and overmarketing of opioids in certain areas such as North America and Australia and has lead to "opioid crisis", and science is called upon to resolve this public health threat (48). Although opioids are effective painkillers, their side effects necessitate a careful approach in chronic non-cancer pain states (49).

In USA, the number of opioid prescriptions written in 1998 was 100 million, increasing to 190 million prescriptions in 1998 and 290 million prescriptions in 2017. Consequently, more then ten million USA citizens are using prescription opioids for nonmedical reasons, and about 2 million people were diagnosed with opioid addiction (47). According to the Centers for Disease Prevention (CDC), more than 33,000 Americans died from an opioid overdose in 2015, a number similar to the 35,000 and 36,000 deaths that were attributed to motor vehicle accidents and firearms in the same year (50).

These figures are a call to action and $\mathrm{CDC}$ has issued a guideline for primary care physicians with the aim to reduce opioid prescriptions for chronic pain except in cases of cancer treatment, palliative care and end of life care (51). This guideline is supported by weak evidence about efficacy of opioids for long-term management of chronic non-cancer pain (52). Furthermore, systematic review that analyzed randomized controlled trials and observational studies about effectiveness and risks of long-term opioid therapy for chronic pain was recently published (53). After searching the literature, the authors reported that they could find "no study of opioid therapy versus no opioid therapy evaluated long-term (>1 
year) outcomes related to pain, function, quality of life, opioid abuse, or addiction", and therefore there is "insufficient evidence to determine the effectiveness of long-term opioid therapy for improving chronic pain and function" (53).

Based on these data, Erdek and Pronovost have suggested that the dilemma regarding overprescribing and undeprescribing of opioids requires "a balanced approach based on an ethical framework; policy changes will need to be implemented in order to effect a more rational approach to the use of opioids; and as with any change, the new policies will likely defend against some risks and introduce new ones, often requiring iterative policy changes" (47).

Policy changes that have been introduced to halt opioid crisis appear to be effective. Drug monitoring programs introduced in USA were associated with lower opioid-related mortality rates (54). Particularly states where these drug monitoring programs had robust characteristics, such as monitoring higher numbers of drugs with abuse potential and updating their data at least weekly, had greater reductions in deaths, compared to other states whose drug monitoring programs did not have these characteristics (54).

If opioid therapy has to be prescribied for chronic noncancer pain, physicians need to schedule frequent follow-up visit to assess improvement and perform urine drug testing to monitor patient compliance (47). Furthermore, physicians need to engage in open discussions with patients and their families about benefits and harms of opioid therapy. Healthcare systems and all its relevant stakeholders have an obligation to optimize patient satisfaction, while minimizing harms to individuals suffering from chronic pain and to society at large (47). Countries in different continents have started responding to opioid epidemic with prescribing guidelines that need to ensure that opioids will be prescribed for appropriate indications only, in limited doses, for carefully selected patients. Additionally, patients need to be advised on safe use of opioids (55). Pain community has reached a broad consensus that opioid epidemics that we are witnessing in certain countries need to be addressed urgently and that other countries should be protected from similar negative outcomes (55).

The problems with opioid crisis may not generalize to the rest of the world; hopefully there are mechanisms in place in each country to prevent this. This also depends on health care resources of each country. The opioid crisis in the USA is a consequence of direct to consumer advertising, untruthful marketing of opioids to physicians and the lack of physician education about pain and its treatment. Each of these factors needs to be studied by every country to make sure that they do not replicate these mistakes. Ultimately, it could be argued that pain education in curricula of healthcare professionals needs due attention.

\section{Precariousness of promoting pain management as a right}

We now have sufficient evidence about inadequate treatment of pain that we can talk about "ethics of undertreatment" and "ethics of underprescribing" (26). However, we also see now how opioid crisis is raising additional set of ethical questions. Thus, promoting pain management as a human right as a legal right may lead to patients and public to request any analgesic they want. The erroneous interpretation of "right to pain relief" may potentially disrupt the basic tenets of clinical assessments by physicians and other healthcare workers (26).

Likewise, it is important to balance the message regarding pain management as a right because not all types of pain can be adequately treated (56). Therefore, while promoting pain management as a human right, we have to be careful to also convey 
the message that "pain relief is not the right to a pain-free life" as there is no guarantee of perfection in medicine (26). If pain management as a human right is interpreted as a right to total analgesia, this will easily lead to frustration among patients and their carers and potentially to litigation (56). Therefore, whenever we talk about pain management as a human right, healthcare professionals need to make clear that this right implies "reasonable and proportionate" response to the intensity and type of pain a person is experiencing (26).

On the other side, it has been argued that promoting pain management as human right can also have negative unintended consequences among healthcare professionals who may see such movements as a potential threat to their clinical judgment and autonomy, and in response become more rigid and defensive, ignoring the clinical guidelines and recommendations for best practices (26).

Thus, education is crucial, both of patients and their carers, as that of healthcare workers. Patients and their carers need to be educated by their attending healthcare staff in what they can realistically expect from the current state of medical science. For education of healthcare workers we need institutional acceptance of pain-related curricula on all levels of professional education. In this respect, IASP made significant advances towards improving professional training about pain by publishing multiple curricula, which cover both core curriculum about pain education and discipline-specific curricula. These curricula are intended to help in establishing teaching courses on acute, chronic and cancer pain at various educational levels, including both undergraduate and graduate level. All these curricula are freely available online, and they were last updated in May 2012. These curricula include medical, legal and ethical aspects related to pain assessment and treatment (57).

\section{Conclusion}

Pain management is fundamental to good clinical practice. Patients do have the right to pain management, but also patient rights have limits, which may be limited by other competing rights, and also rights of their physicians. Treatment of pain must be medically, ethically and economically justified. Attending physician always needs to evaluate a patient thoroughly, and recommend evidence-based treatment for pain, while educating patients about what realistically can be expected from the treatment. Healthcare workers have an obligation to continuously improve their knowledge about pain management, including medical, legal and ethical aspects related to pain.

\section{What is already known on this topic}

For almost two decades now the pain management has been promoted as a fundamental human right. Legal issues and ethical declarations related to pain have also been accumulating, as well as elaborations about precarious issue of pain management, particularly in sensitive cases such as care for terminally ill patients. Major international organizations realized that they need to devote particular attention to ethics and legal aspects of pain.

\section{What this study adds}

In this review we summarized the main legal and ethical aspects of pain management, with particular focus on relevant international declarations and ethical codes and specific cases that physicians should be aware of. Underprescribing and overprescribing of pain therapies can be associated with accusations of negligence, elderly abuse and euthanasia attempts. We also addressed novel controversies related to ethics of the current opioid crisis, perils of promoting pain management as a human right, and pointed out what major international organization for the study of pain recommends as curricula for adequate education of healthcare workers about pain management.

Authors' contributions: Conception and design: MJ; Acquisition, analysis and interpretation of data: M) and LP; Drafting the article: MJ and LP; Revising it critically for important intellectual content: $\mathrm{MJ}$ and LP; Approved final version of the manuscript: MJ and LP.

Conflict of interest: The authors declare that they have no conflict of interest. 


\section{References}

1. Goldberg DS, McGee SJ. Pain as a global public health priority. BMC Public Health. 2011;11:770.

2. Jackson T, Thomas S, Stabile V, Shotwell M, Han X, McQueen K. A Systematic Review and MetaAnalysis of the Global Burden of Chronic Pain Without Clear Etiology in Low- and Middle-Income Countries: Trends in Heterogeneous Data and a Proposal for New Assessment Methods. Anesth Analg. 2016;123(3):739-48.

3. Global Burden of Disease Study 2013 Collaborators. Global, regional, and national incidence, prevalence, and years lived with disability for 301 acute and chronic diseases and injuries in 188 countries, 1990-2013: a systematic analysis for the Global Burden of Disease Study 2013. Lancet. 2015;386(9995):743-800

4. Nicolson SE, Caplan JP, Williams DE, Stern TA. Comorbid pain, depression, and anxiety: multifaceted pathology allows for multifaceted treatment. Harv Rev Psychiatry. 2009;17(6):407-20.

5. Dosenovic S, Jelicic Kadic A, Boban M, Biocic M, Boric K, Cavar M, et al. Interventions for Neuropathic Pain: An Overview of Systematic Reviews. Anesth Analg. 2017;125(2):643-52.

6. Tracey I, Bushnell MC. How Neuroimaging Studies Have Challenged Us to Rethink: Is Chronic Pain a Disease? J Pain. 2009;10(11):1113-20.

7. Taylor AM, Phillips K, Taylor JO, Singh JA, Conaghan PG, Choy EH, et al. Is Chronic Pain a Disease in Its Own Right? Discussions from a PreOMERACT 2014 Workshop on Chronic Pain. J Rheumatol. 2015;42(10):1947-53.

8. Cohen M, Quintner J, Buchanan D. Is chronic pain a disease? Pain Med. 2013;14(9):1284-8.

9. Niv D, Devor M. Chronic pain as a disease in its own right. Pain Pract. 2004;4(3):179-81.

10. Gregory J, McGowan L. An examination of the prevalence of acute pain for hospitalised adult patients: a systematic review. J Clin Nurs. 2016;25(56):583-98.

11. Boric K, Boric M, Boric T, Puljak L. Analysis of perioperative pain management in vascular surgery indicates that practice does not adhere with guidelines: a retrospective cross-sectional study. J Pain Res. 2017;10:203-9.

12. Biocic M, Vidosevic D, Boric M, Boric T, Giunio L, Fabijanic D, et al. Anesthesia and perioperative pain management during cardiac electronic device implantation. J Pain Res. 2017;10:927-32.

13. Lesin M, Domazet Bugarin J, Puljak L. Factors associated with postoperative pain and analgesic consumption in ophthalmic surgery: A systematic review. Surv Ophthalmol. 2015;60(3):196-203.

14. Lesin M, Sundov ZD, Jukic M, Puljak L. Postoperative Pain in Complex Ophthalmic Surgical Procedures: Comparing Practice with Guidelines. Pain Med. 2014;15(6):1036-42.

15. Stewart WF, Ricci JA, Chee E, Morganstein D, Lipton R. Lost productive time and cost due to common pain conditions in the US workforce. JAMA. 2003;290(18):2443-54.

16. Gaskin DJ, Richard P. The economic costs of pain in the United States. J Pain. 2012;13(8):715-24.

17. Mogil JS, Simmonds K, Simmonds MJ. Pain research from 1975 to 2007: a categorical and bibliometric meta-trend analysis of every Research Paper published in the journal, Pain. Pain. 2009;142(1-2):48-58.

18. Fleegler EW, Schechter NL. Pain and Prejudice. JAMA Pediatr. 2015;169(11):991-3.

19. Krnic D, Anic-Matic A, Dosenovic S, Zezelic S, Draganic P, Puljak L. National consumption of opioid and nonopioid analgesics in Croatia: 20072013. Ther Clin Risk Manag. 2015;11:1305-14.

20. Brennan F, Carr DB, Cousins M. Pain management: a fundamental human right. Anesth Analg. 2007;105(1):205-21.

21. Lohman D, Schleifer R, Amon JJ. Access to pain treatment as a human right. BMC Medicine. 2010;8.

22. Fishman SM. Recognizing pain management as a human right: a first step. Anesth Analg. 2007;105(1):8-9.

23. Somerville M. Margaret Somerville: putting medicine, ethics and the law under one roof. Interview by Bill Trent. CMAJ. 1987;137(10):945-7.

24. Pandit MS, Pandit S. Medical negligence: Coverage of the profession, duties, ethics, case law, and enlightened defense - A legal perspective. Indian J Urol. 2009;25(3):372-8.

25. Hunter S. Determination of moral negligence in the context of the undermedication of pain by nurses. Nurs Ethics. 2000;7(5):379-91.

26. Brennan F, Cousins MJ. Pain relief as a human right. Pain: Clinical Updates. 2004;12(5):1-4.

27. Rich BA. Physicians' legal duty to relieve suffering. West J Med. 2001;175(3):151-2.

28. Bergman v Wing Chin, MD and Eden Medical Center. Court case No. H205732-1. Superior Court of California, County of Alameda, Southern Division. 1999.

29. Sunara P, Krnic D, Puljak L. Adverse drug reactions of non-opioid and opioid analgesics report- 
ed to Croatian national authority from 2007 to 2014. Acta Med Acad. 2017;46(2):94-104.

30. Vansweevelt T. Comparative legal aspects of pain management. Med Law. 2008;27(4):899-912.

31. Fidahic M, Dogan K, Sapunar D, Puljak L. National survey of pain clinics in Croatia: Organization and services. Acta Med Acad. 2015;44(1):18-30.

32. Gillon R. Beneficence: doing good for others. Br Med J (Clin Res Ed). 1985;291(6487):44-5.

33. AMA. AMA Code of Medical Ethics' Opinions on Care at the End of Life. Virtual Mentor. 2013;15(12):1038-40.

34. Parsa-Parsi RW. The Revised Declaration of Geneva: A Modern-Day Physician's Pledge. JAMA. 2017;318(20):1971-2.

35. WMA. International Code of Medical Ethics. The World Medical Association, Inc.; 2006. [cited 2018 Mar 22] Available from: https://www.wma.net/ policies-post/wma-international-code-of-medical-ethics/.

36. WMA. Declaration of Helsinki. The World Medical Association, Inc.; 2013. [cited 2018 Mar 22] Available from: https://www.wma.net/policiespost/wma-declaration-of-helsinki-ethical-principles-for-medical-research-involving-human-subjects/.

37. WMA. Declaration of Lisbon on the rights of the patient. The World Medical Association, Inc.; 2015. [cited 2018 Mar 22] Available from: https:// www.wma.net/policies-post/wma-declaration-oflisbon-on-the-rights-of-the-patient/.

38. Bosek MS. Reaffirming a primary commitment to nonmaleficence. JONAS Healthc Law Ethics Regul. 2001;3(2):31-4.

39. Gillon R. Primum-Non-Nocere and the Principle of Non-Maleficence. Br Med J. 1985;291(6488): 130-1.

40. AAPM. Ethics charter from American Academy of Pain Medicine. Pain Med. 2005;6(3):203-12.

41. IASP. Declaration of Montreal. International Association for the Study of Pain; 2010. [cited 2018 Mar 22] Available from: https://www.iasp-pain. org/DeclarationofMontreal.

42. IASP. International Association for the Study of Pain; 2017. [cited 2018 Mar 22] Available from: https://www.iasp-pain.org/.

43. IASP. Ethical Guidelines for Pain Research in $\mathrm{Hu}$ mans. International Association for the Study of Pain; 2017. [cited 2018 Mar 22] Available from: https://www.iasp-pain.org/Education/Content. aspx?ItemNumber $=1213$.

44. Lo B. Assessing decision-making capacity. Law Med Health Care. 1990;18(3):193-201.
45. Riddick FA, Jr. The code of medical ethics of the American Medical Association. Ochsner J. 2003;5(2):6-10.

46. Bockhold CR, Hughes AK. The ethics of opioids for chronic noncancer pain. Nursing (Lond). 2016;46(10):63-7.

47. Erdek MA, Pronovost PJ. The need for an ethics framework for the use of opioids in the treatment of chronic nonmalignant pain. Pain Manag. 2017;7(4):229-31.

48. Volkow ND, Collins FS. The Role of Science in Addressing the Opioid Crisis. N Engl J Med. 2017;377(4):391-4.

49. Els C, Jackson TD, Kunyk D, Lappi VG, Sonnenberg B, Hagtvedt R, et al. Adverse events associated with medium- and long-term use of opioids for chronic non-cancer pain: an overview of Cochrane Reviews. Cochrane Database Syst Rev. 2017;10:CD012509.

50. Barnett ML, Gray J, Zink A, Jena AB. Coupling Policymaking with Evaluation - The Case of the Opioid Crisis. N Engl J Med. 2017;377(24):2306-9.

51. Dowell D, Heagerich TM, Chour R. CDC Guideline for Prescribing Opioids for Chronic Pain - United States, 2016. MMWR Recomm Rep. 2016;65(No. RR-1):1-49.

52. Noble M, Treadwell JR, Tregear SJ, Coates VH, Wiffen PJ, Akafomo C, et al. Long-term opioid management for chronic noncancer pain. Cochrane Database Syst Rev. 2010(1):CD006605.

53. Chou R, Turner JA, Devine EB, Hansen RN, Sullivan SD, Blazina I, et al. The effectiveness and risks of long-term opioid therapy for chronic pain: a systematic review for a National Institutes of Health Pathways to Prevention Workshop. Ann Intern Med. 2015;162(4):276-86.

54. Patrick SW, Fry CE, Jones TF, Buntin MB. Implementation Of Prescription Drug Monitoring Programs Associated With Reductions In Opioid-Related Death Rates. Health Aff (Millwood). 2016;35(7):1324-32.

55. Hauser W, Schug S, Furlan A. The opioid epidemic and national guidelines for opioid therapy for chronic noncancer pain: a perspective from different continents. Pain Reports. 2017;2(3):e599.

56. Haddox JD, Aronoff GM. Commentary: the potential for unintended consequences from public policy shifts in the treatment of pain. J Law Med Ethics. 1998;26(4):350-2, 263.

57. IASP. IASP Curricula. International Association for the Study of Pain; 2017. [cited 2018 Mar 22] Available from: https://www.iasp-pain.org/Education/CurriculaList.aspx. 